\title{
Associação do perfil microbiológico com alterações citológicas em mulheres quilombolas atendidas nas unidades básicas de saúde
}

\author{
Association of the microbiological profile with cytological changes in \\ quilombolas women at the basic health units
}

Francisca Bruna Arruda Aragão ${ }^{1}$ (D), Gerusinete Rodrigues Bastos dos Santos ${ }^{2}$ (D), Walder Jansen de Mello Lobão ${ }^{3}$ (D), Anderson Pereira de Oliveira ${ }^{4}$ (D), Silvio Gomes Monteiro ${ }^{5}$ (D), Lana Meireles Santos $^{6}$ (D), Andréa Dias Reis ${ }^{7}$ (D), Marcelino Santos Neto ${ }^{8}$ (D), José Eduardo Batista ${ }^{9}$ (D)

\begin{abstract}
RESUMO
Objetivo: Analisar o perfil microbiológico e relacionar com as alterações citológicas de mulheres quilombolas que possuem lesões cérvico-vaginais. Material e Métodos: Este foi um estudo de corte transversal de 5 meses, baseado em 154 mulheres quilombolas, na faixa etária de 13 a 74 anos, registradas no Sistema Único de Saúde (SUS) e que possuem lesões cérvico-vaginais. Resultados: Mulheres com idade $>45$ anos $(43,5 \%)$ foram as que mais realizaram exames Papanicolaou, seguido das mulheres com 31 a 45 anos $(31,2 \%)$ e posteriormente $\leq 30$ anos (25,3\%). A infecção mais comum em mulheres com idade $\leq 30$ foi Gardnerella sp. $(35,8 \%)$, já em mulheres na faixa de 31 a 45 anos foi Lactobacillus sp. (47,9\%). A prevalência global das alterações citológicas foi de 7,8\%, com maior frequência na faixa de 31 a 45 anos. Conclusão: As mulheres com vaginose bacteriana apresentaram maior prevalência de atipias celulares e não houve associação estatisticamente significante entre faixa etária e alterações cérvico-vaginais, bem como, a microbiota não apresentou associação com anormalidades citológicas.
\end{abstract}

Palavras-chave: Teste de Papanicolau; Colo do Útero; Esfregaço Vaginal; Prevalência.

\begin{abstract}
Aim: Analyzing the microbiological profile and associate it with cytological alterations in quilombola women with cervical-vaginal lesions. Material and Methods: This was a 5-month cross-sectional study based on 154 quilombola women, in the 13 to 74 years age group, recorded in the Sistema Único de Saúde (SUS) with cervical-vaginal lesions. Results: Women aged 45 years and older $(43.5 \%)$ had the most Pap smears, followed by women in the 31 to 45 years (31,2\%) and $\leq 30$ years old $(25,3 \%)$. The most common infection in women of $\leq 30$ years old was Gardnerella $(35,8 \%)$ and in the 31 to 45 years group was Lactobacillus (47,9\%). The overall prevalence of cytological abnormalities was $7.8 \%$, with higher frequency in the 31 to 45 years group. Conclusion: The microbiological profile in the quilombola women with bacterial vaginosis had the highest cellular atypias prevalence and no statistically significant association was found between the age range and cervical-vaginal changes, as well as the microbiota had no association with cytological abnormalities.
\end{abstract}

Keywords: Papanicolaou Test; Cervix Uteri; Vaginal Smears; Prevalence.

1. Doutoranda no Programa Interunidades de Pós-Graduação de Doutoramento em Enfermagem. Escola de Enfermagem de Ribeirão Preto, Universidade de São Paulo (EERP-USP), Ribeirão Preto (SP), Brasil.

2. Mestre pelo Programa Saúde do Adulto e Criança. Universidade Federal do Maranhão (UFMA), São Luís (MA), Brasil.

3. Mestre pelo Programa Ciências da Saúde. UFMA, São Luís (MA), Brasil.

4. Farmacêutico generalista. UFMA, São Luís (MA), Brasil.

5. Docente. Departamento de Biologia, UFMA, São Luís (MA), Brasil.

6. Docente. Departamento de Medicina, UFMA, Pinheiro (MA), Brasil.

7. Doutoranda no Programa Ciências da Motricidade. Faculdade de Ciências e Tecnologia, Universidade Estadual Paulista (UNESP), Presidente Prudente (SP), Brasil.

8. Docente. Departamento de Enfermagem, UFMA, Imperatriz (MA), Brasil.

9. Docente. Departamento de Patologia, UFMA, São Luís (MA), Brasil.

$\square$ José Eduardo Batista. Departamento de Patologia-Centro de Ciências Biológicas e da Saúde, Universidade Federal do Maranhão, Avenida dos Portugueses S/N. CEP: 65025-560. São Luís (MA), Brasil. jbatistaufma@gmail.com I Recebido: 17/03/2019 | Aprovado: 09/09/2019 


\section{INTRODUÇÃO}

A prevenção do câncer do colo do útero por meio do exame citopatológico ampliou a oferta dos exames em todos os Estados do País com temáticas de reorientar o sistema de saúde para a Atenção Básica, fortalecer a prevenção como uma das ações básicas na assistência à saúde da mulher, contribuir para a criação de protocolos de padronização da coleta de material cervical, com seguimento e condutas frente a cada tipo de alteração cervical, incluindo a cirurgia de alta frequência (CAF) para tratamento das lesões pré-invasoras ${ }^{1}$.

Embora o principal propósito da citologia cérvico-vaginal seja a detecção das lesões precursoras do câncer cervical, o achado de condições infecciosas/reativas também pode contribuir para a saúde da mulher ${ }^{2}$. Um dos fatores de risco para o câncer de colo uterino é o histórico de infecções sexualmente transmissíveis, sendo comprovada esta relação por vários estudos epidemiológicos realizados no Brasil ${ }^{3}$. Dessa forma, tem crescido o interesse na utilização do exame preventivo do câncer de colo uterino para o reconhecimento de infecções cérvico-vaginais como uma importante alternativa diagnóstica ${ }^{4}$.

As vulvovaginites são um dos problemas ginecológicos mais incômodos e comuns que afetam a saúde da mulher e podem ser definidas como inflamações que acometem as paredes vaginais, causando alterações do $\mathrm{pH}$ local, prurido e às vezes secreções. São causadas por bactérias (vaginose bacteriana), por fungos (vulvovaginite fúngica), protozoários (tricomoníase), e também por microrganismos associados chamadas de vulvovaginites mistas ${ }^{5}$. Alguns desses processos infecciosos resultam do desequilíbrio da microbiota vaginal devido ao muco cervical, fluxo menstrual, excitação, relação sexual, causas hormonais e também durante a gestação, e o estresse, deixando o ambiente alcalino e causando um aumento do $\mathrm{pH}$ vaginal com uma predisposição à ocorrência de vaginites ${ }^{2,6}$.

Trabulsi7 (2008) define vaginite como "uma inflamação da vagina caracterizada por corrimento, odor, irritação e prurido". Ou seja, vaginite é um termo para qualquer infecção ou inflamação na vagina. O termo vaginose bacteriana é usado para a denominação clínica de infecção vaginal de bactérias como: Gardnerella vaginalis, Mycoplasma hominis, Mobiluncus sp., Bacteroides sp., Provetella melaninogenica e Bifidobacterium sp.? A vaginose bacteriana caracteriza-se por um desequilíbrio da microbiota vaginal, ocorrendo o aumento de bactérias anaeróbias nessa região ${ }^{5}$.

A importância de identificar micro-organismos causadores de lesões reside no fato de que estes agentes comumente acometem o colo uterino e acabam atuando na chamada zona de transformação, estimulando a substituição da mucosa do tipo glandular em mucosa recoberta por epitélio escamoso. Esse processo é conhecido como metaplasia escamosa e considera-se que nele exista maior propensão à gênese do carcinoma do colo uterino, sobretudo porque estas células são mais permissivas à infecção por HPV8.

Pouco se sabe sobre essas alterações citológicas em mulheres quilombolas e sobre o perfil microbiológico dessas mulheres. Há necessidade de realizar mais pesquisas envolvendo esses grupos sociais, uma vez que se observa uma menor atenção à saúde desta população quando comparada à população de modo geral ${ }^{9}$. Diante do exposto, o objetivo deste estudo é avaliar o perfil microbiológico e sua possível associação com alterações citológicas em material cérvico-vaginal em mulheres quilombolas.

\section{MATERIAIS E MÉTODOS}

\section{Amostragem}

Trata-se de um estudo de corte transversal, com amostra constituída de mulheres quilombolas usuárias do Sistema Único de Saúde (SUS), de municípios do Maranhão, da Região do Litoral Leste, para rastreamento das doenças sexualmente transmissíveis e lesões precursoras do câncer do colo uterino. As mulheres que atenderam ao convite, preencheram os critérios de inclusão, concordaram em assinar o Termo de Consentimento Livre e Esclarecido - TCLE e são sexualmente ativas, foram incluídas no estudo.

Foram excluídas as gestantes, mulheres submetidas a cirurgias no colo uterino e portadoras de déficit cognitivo que prejudicasse o entendimento das respostas para preenchimento do formulário 
específico, bem como amostras que apresentaram esfregaço cérvico-vaginal insatisfatório.

O estudo compreendeu o período de fevereiro a junho de 2016, no qual foram atendidas 154 mulheres com idades variando entre 15 e 75 anos. As participantes eram residentes nos quilombos e cadastradas nas áreas de abrangência das equipes saúde da família. Utilizou-se uma ficha cadastral para entrevista das mulheres no momento da coleta, constando as seguintes informações das usuárias: nome, idade, número do prontuário, data da coleta do exame fitopatológico e da entrega do resultado, descrição do laudo citopatológico e flora microbiana. Foram incluídas as variáveis demográficas, laudos citopatológicos com alterações cervicais benignas e malignas e flora microbiana. $O$ estudo foi aprovado pelo Comitê de Ética da Universidade Federal do Maranhão com o parecer $N^{\circ}$ 1.502.349.

\section{Cálculo do tamanho amostral}

O cálculo do tamanho amostral das mulheres quilombolas foi realizado no programa estatístico PASS 15 (Power Analysis and Sample Size Software $)^{10}$ e com os seguintes parâmetros: prevalência de $10 \%$ de DSTs em populações quilombolas em Turiaçu (MA), nível de significância (a) de $5 \%$, erro tolerável de $7 \%$, poder de teste de $80 \%$, resultando numa amostra de 154 mulheres $^{11}$.

\section{Análise estatística}

O banco de dados foi organizado em planilha do programa Microsoft Office Excel 2007. O teste de qui-quadrado foi utilizado para a análise bivariada para identificar associação entre as variáveis independentes (variáveis sociodemográficas) com a variável dependente (presença ou não de lesão do colo útero). A análise dos dados foi realizada no programa NCSS 11 Statistical Software ${ }^{12}$, adotando o nível de significância de $5 \%(p<0,05)$.

\section{Análise citológica}

$\mathrm{Na}$ apresentação e análise dos resultados, as alterações cervicais obedeceram à nomencla- tura brasileira para laudos cervicais: lesão intraepitelial de baixo grau, metaplasia escamosa imatura, lesão intraepitelial de alto grau e células atípicas escamosas de significado indeterminado possivelmente não neoplásico. As mulheres foram agrupadas em faixas etárias diferentes na apresentação e análise dos resultados. Na análise dos exames citológicos foi verificada por um profissional farmacêutico e bioquímico, logo após revisada por dois profissionais especializados em citologia.

\section{RESULTADOS}

Todas as participantes do estudo com idade entre 13 e 74 anos realizaram o exame citopatológico. A Tabela 1 demonstra a distribuição de mulheres por faixa etária que realizaram o Papanicolaou. Dos registros foi desconsiderado algumas lâminas, uma vez que o material foi insatisfatório ou ilegível, totalizando 8 mulheres com alterações não identificadas. Pode-se relatar também a faixa etária do início de atividade sexual e da menarca, se o uso de contraceptivo é comum entre essas mulheres, número de parceiros, sinais de DST, grau de escolaridade e quantas já haviam realizado o exame de Papanicolaou pelo menos uma vez previamente ao estudo.

\section{Tabela 1}

Características clinicas e sociodemográficas das Mulheres Quilombolas.

\begin{tabular}{lcc}
\hline & $\mathrm{N}$ & $\%$ \\
\hline Idade & & \\
$\quad<30$ & 39 & 25,3 \\
$31-45$ & 48 & 31,2 \\
$\quad>45$ & 67 & 43,5 \\
IAS & & \\
$\quad<16$ & 66 & 42,9 \\
$\quad>16$ & 88 & 57,1 \\
No de Parceiros & & \\
$\quad 1$ & 81 & 52,6 \\
$\quad+1$ & 73 & 47,4 \\
Idade da Menarca & & \\
$\quad<12$ & 62 & 40,3 \\
$>12$ & 92 & 59,7 \\
Sinais de DSTs & & \\
$\quad$ Sim & 48 & 31,2 \\
Não & 106 & 68,8 \\
\hline & & (Continua...)
\end{tabular}


Tabela 1 (Continuação)

\begin{tabular}{lcc}
\hline & $\mathrm{N}$ & $\%$ \\
\hline Uso de Contraceptivo & & \\
Sim & 49 & 31,8 \\
$\quad$ Não & 105 & 68,2 \\
Exame de Papanicolau & & \\
Sim & 135 & 87,7 \\
Não & 19 & 12,3 \\
Escolaridade & & \\
Ensino Médio & 12 & 7,8 \\
Ensino Fundamental & 67 & 43,5 \\
Analfabetas & 75 & 48,7 \\
\hline
\end{tabular}

Siglas: AS = Inicio de Atividade Sexual, DSTs= Doenças Sexualmente Transmissíveis.

A Tabela 2 expressa a prevalência nos diferentes resultados citológicos de acordo com a faixa etária na amostra estudada. Apesar de não ter diferença significativa, clinicamente pode-se observar que a faixa etária que apresentou maior prevalência dos resultados com inflamação foi com idade $>45$ anos. Em relação aos demais resultados citológicos houve distribuição semelhante entre as faixas etárias.
Tabela 2

Prevalência nos diferentes resultados citológicos de acordo com a faixa etária em 154 mulheres.

\begin{tabular}{|c|c|c|c|c|c|c|c|}
\hline Resultados & \multicolumn{2}{|c|}{$<30$} & \multicolumn{2}{|c|}{$31-45$} & \multicolumn{2}{|c|}{$>45$} & \multirow{2}{*}{$p$} \\
\hline Citológicos & No & $(\%)$ & No & $(\%)$ & No & $(\%)$ & \\
\hline Inflamação & 33 & 84,6 & 41 & 85,4 & 60 & 89,6 & \multirow{7}{*}{0,758} \\
\hline ASC-US & 1 & 2,6 & 1 & 2,1 & - & 0,0 & \\
\hline LSIL & - & 0,0 & 2 & 4,2 & 2 & 3,0 & \\
\hline ASC-H & - & 0,0 & 1 & 2,1 & - & 0,0 & \\
\hline HSIL & 2 & 5,1 & 1 & 2,1 & 2 & 3,0 & \\
\hline Insatisfatória & 3 & 7,7 & 2 & 4,2 & 3 & 4,5 & \\
\hline Total & 39 & 25,3 & 48 & 31,2 & 67 & 43,5 & \\
\hline
\end{tabular}

Siglas: ASC-US: Células Escamosas Atípicas de Significado Indeterminado; ASC-H: Células escamosas atípicas de significado indeterminado não se podendo excluir lesão de alto grau; LSIL: Lesão Intraepitelial escamosa de baixo grau; HSIL: Lesão Intraepitelial escamosa de alto grau.

Na Tabela 3 podemos verificar que não houve associação entre microbiota e anormalidades citológicas, porém, pode-se observar maior quantidade de casos de Gardnerella sp. associada a HSIL $(16,7 \%)$ e de bacilos com LSIL $(16,7 \%)$.

\section{Tabela 3}

Relação entre Microbiota e Anormalidades Citológicas.

\begin{tabular}{lrrrrrrrrr}
\hline Microbiota & HSIL & \multicolumn{1}{c}{$\%$} & ASC-H & $\%$ & LSIL & \multicolumn{1}{c}{$\%$} & ASC-US & $\%$ & P \\
\hline Gardnerella & 2 & 16,7 & 1 & 8,3 & 1 & 8,3 & 0 & 0 & 0 \\
Bacilos & 0 & 0 & 1 & 8,3 & 2 & 16,7 & 0 & 0,3 & 0,364 \\
Lactobacillus & 1 & 8,3 & 0 & 0 & 0 & 0 & 1 & 0 & 0 \\
Cocos & 1 & 8,3 & 1 & 8,3 & 0 & 0 & 0 & 0 & 0 \\
Flora escassa & 1 & 8,3 & 0 & & 0 & 0 & 0 & \\
Total & 5 & 41,7 & 3 & 25,0 & 3 & 25,0 & 1 & 8,3
\end{tabular}

Siglas: ASC-US: Células Escamosas Atípicas de Significado Indeterminado; ASC-H: Células escamosas atípicas de significado indeterminado não se podendo excluir lesão de alto grau; LSIL: Lesão Intraepitelial escamosa de baixo grau; HSIL: Lesão Intraepitelial escamosa de alto grau.

O gráfico 1 demonstra o perfil intra-grupo da microbiota vaginal relacionada com idade das pacientes, em que Lactobacillus sp. esteve presente em 58 mulheres $(39,73 \%)$, com maior prevalência na faixa etária 31-45 anos, Gardnerella sp. em 40 mulheres $(27,40 \%)$, com prevalência mais alta nas mulheres que possuem $\geq 30$ anos, cocos/ bacilos em 16 mulheres $(10,95 \%)$ e outros micro-organismos em 32 (21,92\%), ambos com elevada prevalência na faixa etária $>45$ anos. 


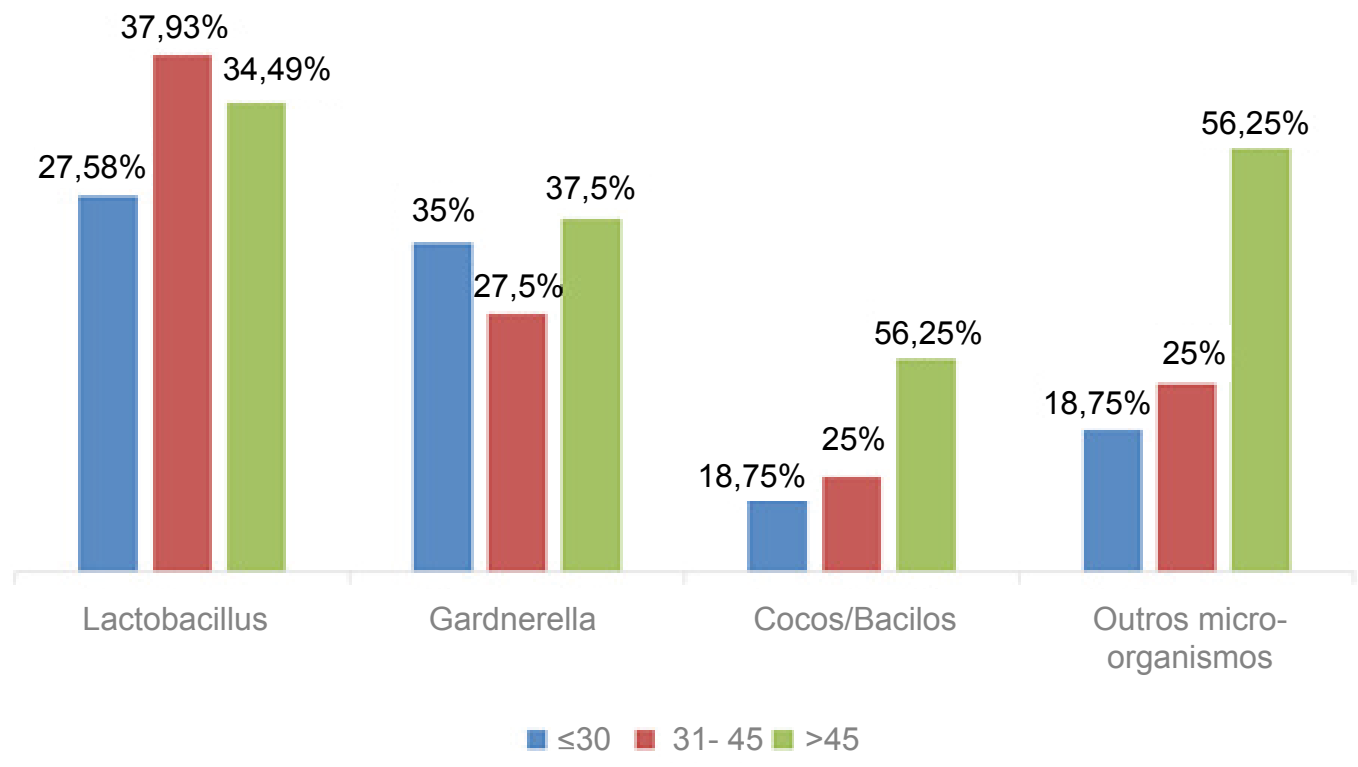

Gráfico 1: Relação do perfil da Microbiota com a idade, considerando cada grupo de micro-organismo como $100 \%$ da distribuição da faixa etária.

\section{DISCUSSÃO}

Desde o conhecimento que o HPV pode estar associado ao desenvolvimento do câncer do colo do útero, vários estudos foram desenvolvidos com o objetivo de identificar cofatores relacionados ao câncer de colo de útero e lesões precursoras ${ }^{13}$.

As 154 mulheres que se submeteram ao exame clínico-ginecológico apresentavam idade que variou entre 13 a 78 anos, com média de 42 anos. Quando analisada a microbiologia desses exames, obteve-se a Gardnerella vaginalis $(35,8 \%)$ com maior prevalência nas mulheres com $\leq 30$ anos. Nossos resultados corroboram com a literatura, pois foram semelhantes com os achados de Gontijo et al. ${ }^{14}$, em que a faixa etária de 20 a 30 anos foi a mais afetada. No trabalho de Tabile et al. ${ }^{15}$, foi possível observar uma diferença com relação a idade mais afetada pela vaginose bacteriana, pois a faixa etária com maior número de casos positivos foi a de 25 a 34 anos, correspondendo a $49,5 \%$ de um total de 277 participantes. A vaginose é considerada infecção vaginal de grande prevalência em mulheres em idade reprodutiva, estando associada a complicações ginecológicas e obstétricas, incluindo doenças inflamatórias pélvica, endometrite, infecções após cirurgias ginecológicas e nascimento prematuro ${ }^{16,17}$.
Os agentes causais da vaginose bacteriana encontram-se presentes em grande parte da população feminina sem provocar sintomas, e as manifestações clínicas se originam de um desequilíbrio da microbiota vaginal na qual ocorre um crescimento excessivo das bactérias anaeróbicas endógenas pré-existentes. Há controvérsias sobre se a vaginose bacteriana pode ou não ser considerada como uma DST. Porém, tem sido sugerido que a vaginose bacteriana é uma doença reforçada pelo sexo, sendo a frequência da relação sexual um fator crítico para contrair a doença ${ }^{18}$.

Apesar de ter sido utilizado nesse estudo apenas o exame de Papanicolaou para o diagnóstico das lesões cervicais e da vaginose bacteriana, não sendo realizados métodos colposcópicos, histológicos e microbiológicos para diagnóstico definitivo, o exame preventivo de Papanicolau tem valor como teste de rastreamento e é amplamente difundido no Brasil por estar inserido no Programa Nacional de Prevenção do Câncer de Colo do Útero ${ }^{19}$, oferecendo às mulheres a oportunidade de realizar este exame rotineiramente.

Mulheres saudáveis apresentam normalmente no fluido vaginal uma prevalência maior de Lactobacillus $s p$. Eles mantêm um ambiente vaginal vigoroso através da produção de ácido láctico, peróxido de hidrogênio, bacteriocinas e outras substâncias ${ }^{15}$. 
Estes produtos possuem propriedades antibacterianas, exercendo um efeito inibitório do crescimento de microrganismos patogênicos. Alguns Lactobacillus $s p$. podem aderir ao epitélio vaginal e, dessa forma, interferir na capacidade de adesão de alguns patógenos $^{16,20}$. É possível que este fato explique os nossos achados, uma vez que dos micro-organismos encontrados neste estudo, o mais prevalente foi compatível com Lactobacillus sp. $(39,73 \%)$. Desta forma, podemos compreender que este fato é característica comum em mulheres saudáveis, já que os Lactobacillus $s p$. são importantes para manutenção do equilíbrio da microbiota vaginal normal.

A partir dos dados de prevalência de agentes infecciosos encontrados neste estudo, podemos comparar nossos resultados aos de outros estudos realizados com as alterações celulares mais prevalentes (lesão de baixo grau e lesão de alto grau) que foram diagnosticadas e ocorreram nas faixas etárias entre 31 e 40 anos, assim como os casos de diagnóstico de atipias celulares. Estudos estes compatíveis com o trabalho de Navarro et al. ${ }^{21}$, que afirmam em seu trabalho que a maior incidência do câncer de colo de útero ocorre em mulheres com idades entre 40 e 60 anos, sendo menos frequentes antes dos 30 anos. Apesar de serem resultados compatíveis com outros estudos, observamos que a inflamação estava presente em $87 \%$ dos casos, entretanto, não houve uma associação estatisticamente significante entre inflamação, vaginose bacteriana e a deteç̧ão de anormalidades citológicas, dado este que pode ser explicado pela singularidade da amostra estudada, diferente do que a literatura relata.

Assim, para estabelecer se realmente existe associação causal entre vaginose bacteriana e lesões precursoras do câncer do colo do útero, seria necessário avaliar os mecanismos moleculares envolvidos na vigência da vaginose bacteriana que possivelmente corroborem com a persistência do HPV e desenvolvimento das lesões cervicais. Em nosso estudo, encontramos respostas clínicas de maior prevalência das lesões cervicais relacionadas com Gardnerella sp. 33,3\% (4/12), porém, sem apresentar associações estatisticamente significantes.

De acordo com os dados apresentados e discutidos anteriormente, podemos presumir uma possível relação do entre o epitélio inflamado e agentes infecciosos com estas alterações sen- do mais prevalentes em mulheres mais jovens. Cabe salientar que a G. vaginalis, por si só, não é um agente causal do processo inflamatório. Os resultados dessa pesquisa reforçam a necessidade de Programas de Prevenção, salientando a importância da realização rotineira do exame citológico, capaz de detectar alterações precoces, a fim de contribuir para a diminuição do número de casos de lesões precursoras do câncer de colo uterino no Brasil e principalmente em populações isoladas.

Há indicações de que populações pertencentes a certos grupos étnicos apresentam maior tendência para apresentarem lesões de alto grau apesar dos avanços significativos nas últimas décadas sobre saúde reprodutiva destas populações ${ }^{22}$. Um fator importante da população quilombola em estudo é a própria condição de isolamento geográfico em seus quilombos, dificuldade de entendimento e aceitação por parte das mulheres sobre a necessidade de exames preventivos, deficiência de infraestrutura, barreiras geográficas e logísticas relacionadas às dificuldades de acesso e a baixa inclusão das mulheres aos programas de prevenção do Câncer do Colo do Útero podem explicar a maior prevalência nas lesões encontradas neste estudo.

\section{CONCLUSÃO}

O presente estudo mostrou que as mulheres com vaginose bacteriana apresentaram maior prevalência de atipias celulares diagnosticadas pelo exame de Papanicolaou em relação às muIheres sem vaginose bacteriana. Entretanto, não houve uma associação significante entre o perfil microbiológico e alterações cérvico-vaginais.

\section{Conflitos de Interesse}

Os autores declaram não haver qualquer conflito de interesse, em potencial, neste estudo.

\section{Financiamento}

O presente estudo foi financiado pela CAPES, AUXPE e FAPEMA. 


\section{REFERÊNCIAS}

1. Ribeiro JC, Andrade SR. Vigilância em saúde e a cobertura de exame citopatológico do colo do útero: revisão integrativa. Texto \& Contexto Enferm (online) [internet]. 2016 [acesso em 07 ago 2019];25(4):1-12. Disponível em: http://www.scielo.br/pdf/tce/v25n4/pt_ 0104-0707-tce-25-04-5320015.pdf

2. Camargo KC, Alves RRF, Baylão LA, Ribeiro AA, Araújo NLAS, Tavares SBN, et al. Secreção vaginal anormal: Sensibilidade, especificidade e concordância entre o diagnóstico clínico e citológico. Rev Bras Ginecol Obstet (online) [internet]. 2015 [acesso em 07 ago 2019]; 37(5):222-8. Disponível em: http://www.scielo.br/pdf/ rbgo/v37n5/0100-7203-rbgo-37-05-00222.pdf

3. Barcelos MRB, Lima RCD, Tomasi E, Nunes BP, Duro SMS, Facchini LA. Qualidade do rastreamento do câncer de colo uterino no Brasil: avaliação externa do PMAQ. Rev Saúde Pública (online) [internet]. 2017 [acesso em 07 ago 2019];51(1):1-13. Disponível em: http://www.scielo.br/pdf/rsp/v51/pt_0034-8910-rsp-S1518-87872017051006802.pdf

4. Tomasi E, Oliveira TF, Fernandes PAA, ThuméE, Silveira DS, Siqueira FV, et al. Estrutura e processo de trabalho na prevenção do câncer de colo do útero na Atenção Básica à Saúde no Brasil: Programa de Melhoria do Acesso e da Qualidade - PMAQ. Rev Bras Saúde Mater Infant (online) [internet]. 2015 [acesso em 07 ago 2019];15(2):171-80. Disponível em: http://www.scielo.br/pdf/rbsmi/v15n2/ 1519-3829-rbsmi-15-02-0171.pdf

5. Silva NC, Rocha TAH, Rodrigues RB, Barbosa ACQ. Equidade na atenção primária à saúde da mulher: uma análise do Brasil e suas regiões. Rev Baiana Saúde Pública (online) [internet]. 2014 [acesso em 07 ago 2019]; 38(2):243-65. Disponível em: https://www.researchgate.net/publication/276859082_Equidade_na_atencao_ primaria_a_saude_da_mulher_uma_analise_do_Brasil_e_suas_regioes

6. Sadovsky ADI, Poton WL, Reis-Santos B, BarcelosMRB, Silva ICM. Índice de Desenvolvimento Humano e prevenção secundária de câncer de mama e colo do útero: um estudo ecológico. Cad Saúde Pública (online) [internet]. 2015 [acesso em 07 ago 2019];31(7):1539-50. Disponível em: http://www.scielo.br/pdf/csp/v31n7/ 0102-311X-csp-31-7-1539.pdf

7. Andújar MTA, López AG, Parra CP, Pérez RL, Casas CC, Gómez MMR, et al. Desquamative Inflammatory Vaginitis: The Unknown. Int J Women's Health Reprod Sci (online) [internet] 2015 [acesso em 07 ago 2019]; 3(3):171-3. Disponível em: https://www.researchgate. net/publication/281876394_Desquamative_Inflammatory_Vaginitis_The_Unknown

8. Santos LN, Castaneda L, AguiarSS, Thuler LCS, Koifman RJ, Bergmann A. Health-related Quality of Life in Women with Cervical Cancer. Rev Bras Ginecol Obstet (online) [internet]. 2019 [acesso em 07 ago 2019];41(4):242-8. Disponível em: http://www.scielo.br/pdf/rbgo/v41n4/ 0100-7203-rbgo-41-04-242.pdf
9. Fernandes ETBS, Nascimento ER, Ferreira SL, Coelho EAC, Silva LR, Pereira COJ. Cervical cancer prevention among quilombola women in the light of Leininger's theory. Rev Gaúch Enferm (online) [internet] 2018 [acesso em 07 ago 2019];39(1):1-8. Disponível em: http://www.scielo.br/pdf/rgenf/v39/en_1983-1447-rgenf-39-01-e2016-0004.pdf

10. PASS 15 Power Analysis and Sample Size Software (2017). NCSS, LLC. Kaysville, Utah, USA, ncss.com/software/pass.

11. Viegas DP, Vargas ID. Promoção à saúde da mulher negra no povoado Castelo, Município de Alcântara, Maranhão, Brasil. Saúde Soc (online) [internet] 2016 [acesso em 07 ago 2019]; 25(3):619-30. Disponível em: http:// www.scielo.br/pdf/sausoc/v25n3/1984-0470-sausoc-25-03-00619.pdf

12. NCSS 11 Statistical Software (2016). NCSS, LLC. Kaysville, Utah, USA, ncss.com/software/ncss.

13. Sousa D.M.D., Chagas A.C.M.A., Vasconcelos C.T.M., Stein A.T. Oriá M.O.B. Development of a clinical protocol for detection of cervical cancer precursor lesions. Rev Lat Am. Enfermagem (online) [internet] 2018 [acesso em 07 ago 2019];26(1):1-9. Disponível em: http://www. scielo.br/pdf/rlae/v26/0104-1169-rlae-26-e2999.pdf

14. Gontijo L.S., Fonseca A.O.D., Bispo K.S. Perfil epidemiológico da doença inflamatória pélvica nas mulheres atendidas nos centros de estratégia saúde da família na cidade de Montes Claros/MG. Rev Bras Pesq Saúde (online) [internet]. 2016 [acesso em 07 ago 2019];18(3): 120-9. Disponível em: http://www.periodicos.ufes.br/ RBPS/article/viewFile/15751/10897

15. Tabile P.M., Lucena H., Chaves J., Fischborn J., Jucá R.B. Características clínicas, prevalência e diagnóstico de vulvovaginites em ambulatório do interior do Rio Grande do Sul. J Health Biol Sci. (online) [internet] 2016 [acesso em 07 ago 2019]; 4(3): 160-5. Disponível em: https:// periodicos.unichristus.edu.br/jhbs/article/view/657/334

16. Bradshaw C.S, Brotman RM. Making inroads into improving treatment of bacterial vaginosis - striving for long-term cure. BMC Infect Dis. (online) [internet] 2015 [acesso em 07 ago 2019];15(1):1-12. Disponível em: https://www.ncbi.nlm.nih.gov/pubmed/26219949

17. Toninato LGD, Irie MMT, Consolaro MEL, Teixeira JJV, Boer CG. Vaginose bacteriana diagnosticada em exames citológicos de rotina: prevalência e características dos esfregaços de Papanicolaou. Rev Bras Anal Clín. (online) [internet]. 2016 [acesso em 07 ago 2019];48(2):1659. Disponível em: http://www.rbac.org.br/wp-content/uploads/2016/06/ARTIGO-12_RBAC-48-2-2016ref.-1205.pdf

18. Lima APW, Rossi CO. Ocorrência de vaginose bacteriana no exame citológico de pacientes de um hospital de Curitiba. Rev Saúde \& Desenvol. (online) [internet]. 2015 [acesso em 07 ago 2019];7(4):166-78. Disponível em: https://www.uninter.com/revistasaude/index.php/ saudeDesenvolvimento/article/view/397/286 
19. Silva LR, Almeida CAPL, Sá GGM, Moura LKB, Araújo ETH. Educação em saúde como estratégia de prevenção do câncer do colo do útero: revisão integrativa. Rev. Prev. Infecç. Saúde. (online) [internet]. 2017 [acesso em 07 ago 2019];3(4):35-45. Disponível em: http://www.ojs.ufpi.br/index.php/nupcis/article/view/ 6708/pdf

20. Africa C.W, Nel J, Stemmet M. Anaerobes and bacterial vaginosis in pregnancy: virulence factors contributing to vaginal colonisation. Int J Environ Res Public Health (online) [internet]. 2014 [acesso em 07 ago 2019]; 11(7):6979-7000. Disponível em: https://www.ncbi. nlm.nih.gov/pmc/articles/PMC4113856/
21. Navarro C, Fonseca AJ, Sibajev A, Souza CIA, Araújo DS, Teles DAF, et al. Cobertura do rastreamento do câncer de colo de útero em região de alta incidência. Rev Saúde Pública (online) [internet]. 2015 [acesso em 07 ago 2019]; 49(1):1-8. Disponível em: https://www.redalyc.org/ pdf/672/67240213014.pdf

22. Botega GCN, Castro MNR, Costa VO, Oliveira JFG, Ulian WL, Sousa FDM, et al. A extensão universitária na prevenção do câncer de colo do útero em comunidades ribeirinhas no estado do Pará. Rev Ciênc Ext. (online) [internet] 2016 [acesso em 07 ago 2019];12(3):22-36. Disponível em: https://ojs.unesp.br/index.php/revista_ proex/article/view/1285 